\title{
Induction Temperature Enhances Antioxidant Enzyme Activity and Osmoprotectants in Tomato
}

\author{
Geeta Biradar $^{1,3}$, R.H. Laxman ${ }^{1}$, M.R. Namratha ${ }^{1}$, M. Thippeswamy ${ }^{1}$, \\ K.S. Shivashankara ${ }^{1}$, T.K. Roy $^{1}$ and A.T. Sadashiva ${ }^{2}$ \\ ${ }^{1}$ Division of Plant Physiology and Biochemistry, ${ }^{2}$ Division of Vegetable Crops, \\ ICAR-Indian Institute of Horticultural Research, Hessaraghatta Lake Post, \\ Bangalore 560 089, India \\ ${ }^{3}$ Department of Botany, Centre for Post Graduate Studies, Jain University, Jayanagar 3rd \\ block, Bengaluru 560011, India \\ *Corresponding author
}

\section{A B S T R A C T}

Keywords

Tomato;

Antioxidant enzymes; Sugars; Temperature induction response

Article Info

Accepted:

12 February 2019

Available Online:

10 March 2019
The temperature increase above the optimum level cause irreversible damage to plant growth and development. Plants respond to high temperature through acclimation (acquired thermotolerance) by adopting several physiological and biochemical mechanisms to overcome high temperature stress. Hence, the present study was done to evaluate tomato genotypes for their thermo tolerance based on the principle of "acquired tolerance'. Four true leaf stage seedlings of fourteen tomato genotypes were subjected to a gradual temperature increase from 33 to $43{ }^{\circ} \mathrm{C}$ for $3 \mathrm{~h}$ followed by challenging temperature of $45^{\circ} \mathrm{C}$ for $3 \mathrm{~h}$. The response of tomato genotypes was assessed by activity of antioxidant enzymes and osmoprotectants. An increase in the activity of SOD, POD and CAT was observed across the genotypes. The accumulation of sugars such as sucrose, inositol, fructose and glucose was higher in all the tomato genotypes subjected to induction treatment. The genotypes Abhinava, Arka Rakshak, Arka Ananya, IIHR-335, IIHR-329 and IIHR-369 showed higher thermo-tolerance with increase in osmoprotectants and by maintaining a strong antioxidant enzyme system.

\section{Introduction}

Tomato (Solanum lycopersicum L.) is one of the most important vegetable, grown all over the world. The occurrence of various abiotic stresses due to climate change would be a challenge to plants in terms of their growth and productivity (Hasanuzzaman et al., 2013). It has been observed that the growth and development of tomato crop is severely affected due to high temperature stress.
However, the global studies predict a 10 to 40 $\%$ probable loss in crop production including tomato in India because of rise in temperature by the end of this century (Aggarwal, 2003). The tomato crop requires an optimum mean daily temperature of $25-30^{\circ} \mathrm{C}$ (Zhang et al., 2005) at the same time, crossing the upper limit above optimum range can affect the plant growth and development (Sato et al., 2000; 2004; 2006; Islam, 2011; Laxman et al., 2018). Many studies have described that the 
decline in productivity of tomato under high temperature is related to physiological and biochemical changes (Zhou et al., 2015, Camejo et al., 2005, Mishra et al., 2012, Laxman et al., 2013).

The effect of high temperature stress on plants results into excess production of superoxide radicals, hydrogen peroxide $\left(\mathrm{H}_{2} \mathrm{O}_{2}\right)$, singlet oxygen and other reactive oxygen species (ROS) in different cellular organelles, which leading to damage of lipids, proteins and pigments. According to Ayala et al., (2014) ROS accumulation causes membrane damage by producing metabolites involved in lipid peroxidation, such as malondialdehyde (MDA) and thiobarbituric acid-reactive substances (TBARS) and ultimately cell death. Plants also respond to highly toxic ROS by several antioxidative detoxification mechanisms to prevent cellular injuries. The mechanism includes production of antioxidant enzymes such as superoxide dismutase (SOD; EC 1.15.1.1), peroxidase (POD; EC 1.11.1.7), catalase (CAT; EC 1.11.1.6) and glutathione reductase (GR; EC 1.8.1.7) and non enzymatic antioxidants such as Carotenoids, flavonoids and ascorbic acids. Tolerance to high temperature stress in crop plants has been associated with an increase in antioxidative capacity (Camejo et al., 2002; Laxman et al., 2014). Hence antioxidant enzymes play a very important role as a defence mechanism for protecting cellular membranes and organelles against ROS (Rivero et al., 2004). However, an increase in temperature leads to an enhanced expression of the antioxidative enzymes until a particular temperature after which they decline as antioxidant enzymes are temperature sensitive and the activation depends on different range of temperatures.

The osmoprotectants (compatible solutes) includes soluble sugars such as sucrose, glucose and fructose. Under various abiotic stresses these osmoprotectants play an active role by increasing the osmotic pressure in the cytoplasm and help in regulation of photosynthesis, partitioning of carbohydrates, lipid metabolism, osmotic adjustment, proteins stabilization and ultimately growth (Rosa et al., 2009). According to Rathinasabapathi (2000) the sugars enhance plant tolerance to several abiotic stresses, such as drought, heat and salinity. Evidences from the earlier studies show that higher accumulation of sugars such as sucrose, fructose and glucose helps in mitigating damages caused by high temperature stress in plants (Miguel et al., 2007 and Zhang et al., 2012). The main role of these sugars as osmoprotectants during stress is protection of membrane and scavenging of radicals and also in regulating the osmotic adjustment in plants (Crowe et al., 1999; Sawhney and Singh, 2002; Krasensky and Jonak, 2012). It is also observed that the accumulation of sugars is directly correlated with the accumulation of ROS to cope with adverse conditions (Roitsch, 1999). In order to enhance tolerance capacity under stress conditions, the plants produce a great amount of osmoprotectants for quenching the toxic ROS (Singh et al., 2015; Keunen et al., 2013)

Under natural conditions, abiotic stress occurs gradually. Plants are therefore exposed to induction stress before severe stress. Several studies have reported that plants have ability to withstand under severe temperature stress upon exposure to gradual temperature stress referred as induction stress. The process of adapting to a severe stress followed by mild stress is known as acquired thermotolerance (Vierling, 1991). According to Hong and Vierling (2000) an acclimated plant will survive better than plants which are directly exposed to high temperature, due to expression of several stress responsive genes which maintain the homeostasis under stress. With this background the present study was carried out to evaluate acquired thermotolerance response of fourteen tomato 
genotypes using temperature induction response (TIR) technique.

\section{Materials and Methods}

\section{Plant material and experimental details}

The Seeds of fourteen tomato genotypes which included 11 genotypes which have shown field tolerance, such as IIHR-329, IIHR-371, IIHR-369, IIHR-335, IIHR-331, Arka Ananya, Abhinava, Arka Rakshak, IIHR-2202, IIHR-2190, Vybhav and 3 susceptible genotypes such as PTR 3, CO-3, Arka Abha were obtained from the Division of Vegetable Crops, and the experiment was conducted at division of Plant Physiology and Biochemistry, ICAR-Indian Institute of Horticultural Research (IIHR), Bengaluru, Karnataka, India $\left(12.97^{\circ} \mathrm{N}\right.$ and $\left.77.56^{\circ} \mathrm{E}\right)$.

The seeds were grown in plastic pots containing sterilized cocopeat in growth chamber at $25^{\circ} \mathrm{C}$, and were watered with Hoagland solution $(20 \mathrm{ml} / \mathrm{pot})$.

At the fourth true leaf stage, a group of seedlings were exposed to induction treatment, a gradual induction temperature of $33^{\circ} \mathrm{C}$ to $43^{\circ} \mathrm{C}$ for 3 hours and subsequently to $45^{\circ} \mathrm{C}$ for 3 hours in the temperature controlled growth chamber. One set was maintained as control under ambient conditions at $25^{\circ} \mathrm{C}$ (Senthil Kumar M and Udayakumar M. 2004).

\section{Estimation of sugars}

Sugars were extracted by following Steppuhn and Wackers (2004) method. With $0.5 \mathrm{~g}$ of the sample extracted with $5 \mathrm{ml}$ of $80 \%$ ethanol.

The extract was evaporated and re-dissolved in mobile phase containing solvent $\mathrm{A}$ and solvent B in 1:1 ratio, filtered and injected to LC-MS/MS (Waters UPLC H class system fitted with TQD MS/MS system) for analysis.

\section{Enzyme extraction and enzyme assays}

Leaf tissue of $0.5 \mathrm{~g}$ was ground to a fine powder with mortar and pestle in cold potassium phosphate buffer $(50 \mathrm{mM}$; $\mathrm{pH} 7.0)$ containing EDTA $(1 \mathrm{mM})$, ascorbate $(2 \mathrm{mM})$ and soluble PVP (1\%). The homogenate was centrifuged (HERMLE Z300 K, Germany) at 12,000 RPM for $15 \mathrm{~min}$ at $4{ }^{\circ} \mathrm{C}$ and the extract was used for the assay of antioxidant enzymes, using UV/VIS spectrophotometer (UV/VIS Spectrometer; PG Instruments, UK) and expressed in units per $\mathrm{mg}$ of protein using standard enzyme (Sigma-Aldrich).

The enzyme assays were performed as per the procedures of Larkindale and Huang (2004). The activity of SOD (EC 1.15.1.1) was determined at $560 \mathrm{~nm}$, and one unit of SOD activity was defined as the amount of enzyme required for inhibition of $50 \%$ nitro blue tetrazolium reduction. The activity of POD (EC 1.11.1.7) was measured as the absorbance due to tetraguaiacol at $450 \mathrm{~nm}$ and the CAT activity was measured at $240 \mathrm{~nm}$. Protein content was measured according to the method of Bradford (1976).

\section{Statistical analysis}

The data were subjected to Analysis of Variance (ANOVA) using AgriStat.

\section{Results and Discussion}

\section{Antioxidant enzyme activity}

\section{SOD activity}

As a power full antioxidant enzyme, SOD activates first line of defence under high temperature stress (Gill and Tuteja, 2010). In the present study an increase in activity of SOD was observed in all the genotypes subjected to heat stress (Fig. 1A). The activity of SOD under control condition ranged from 
0.35 to 2.96 units $\mathrm{mg}^{-1}$ protein while it varied between 0.55 to 8.47 units $\mathrm{mg}^{-1}$ protein under induction treatment among the tested tomato genotypes. However highest increase in activity of SOD over control was recorded in genotypes Arka Rakshak (964.9\%) followed by IIHR-329 (380.3\%) and least increase in enzyme activity was observed in genotypes Arka Abha and CO-3. Enhanced activity of antioxidant enzymes may increases high temperature stress tolerance by detoxification of the heavy load of ROS, which in turn provides protection through homeostasis in plants (Sairam and Tyagi, 2004; Laxman et al., 2014; Revero et al., 2004). Increased SOD activity was observed in tolerant tomato genotypes compared to sensitive genotypes (Laxman et al., 2014).

\section{POD activity}

Like SOD, POD is also an important key antioxidant enzyme which plays an important role in scavenging ROS under high temperature stress. The induction treatment invariably enhanced POD in all the genotypes (Fig. 1B). The POD activity increased in tomato cultivars when subjected to high temperature stress (Revero et al., 2004). Under control condition POD activity varied from 0.003 to 0.093 units $\mathrm{mg}^{-1}$ protein while under induction treatment it ranged between 0.007 to 0.113 units $\mathrm{mg}^{-1}$ protein. Under induction treatment the highest increase in activity of POD over control was recorded in genotypes Arka Rakshak (326.3\%) and IIHR$369(252.1 \%)$ compared to other genotypes where as lowest was recorded in genotypes Arka Abha (53.5\%) and CO-3 (21.73\%).

\section{CAT activity}

CAT is another important enzyme which scavenges ROS, and an increase in CAT activity is related with increase in stress tolerance (Rainwater et al., 1996). The CAT activity increased considerably among the genotypes under induction treatment compared to control seedlings (Fig. 1C). The activity of CAT in control condition ranging from 0.57 to 5.60 units $\mathrm{mg}^{-1}$ protein, while under induction it varied between 1.03 to 7.12 units $\mathrm{mg}^{-1}$ protein. The highest increase in activity of CAT over control was recorded in genotypes IIHR-371 (435.7\%) and IIHR-329 (332.9\%) compared to other genotypes and the lowest activity was recorded in genotypes Arka Abha (39.8\%) and CO-3 (27.3\%). An increase in POD and CAT during exposure to heat stress has been reported in several crops (Jiang and Huang 2001). The highest production of antioxidant enzymes suggests the ability to scavenge ROS under high temperature stress (Xu et al., 2006; Wahid and Close, 2007; Yuan et al., 2011). Overall the higher activity of tested enzymes under induction treatment was mainly because of altered metabolism for acclimation. The activity of antioxidant enzymes differ depending upon tolerance level of different crop varieties, their growth stage and growing season. Hence, an increase in the activity of SOD, POD and CAT is essential for maintaining the cell integrity.

\section{Sugar profiling}

In the present study high temperature stress caused significant increase in sugars in all the genotypes (Table 1). The soluble sugars increase under high temperature stress in tomato plants (Laxman et al., 2013). Among the sugars, sucrose was found to be the major sugar. The sucrose content in control plants ranged from 0.68 to $4.70\left(\mathrm{mg} \mathrm{g}^{-1} \mathrm{fw}\right)$, while under induction treatment it varied between 0.76 and $16.90\left(\mathrm{mg} \mathrm{g}^{-1} \mathrm{fw}\right)$. The genotypes differed significantly when subjected to induction treatment and highest increase in sucrose content over the control was recorded in genotypes, IIHR-329 (1793.1\%) followed by IIHR-2202 (1403.4\%) and the genotype 
Vybhav (10.9\%) recorded lowest content. The plant ability to accumulate sucrose is mainly dependent on sucrose metabolizing enzymes including sucrose phosphate synthase, sucrose synthase and invertases (Miguel et al., 2007).

Inositol was second major sugar which accumulated under high temperature stress in the present study. It ranged from 0.13 to 1.93 $\left(\mathrm{mg} \mathrm{g}^{-1} \mathrm{fw}\right)$ in control and 0.46 to 4.41 ( $\mathrm{mg} \mathrm{g}$ ${ }^{1} \mathrm{fw}$ ). Significantly highest increase in inositol content over the control was recorded in genotypes IIHR-2190 (1142.7\%) followed by IIHR-329 (351.9\%) compared to rest of the genotypes and the lowest content was recorded in genotypes CO-3 (27.2\%) and Arka Abha (27.0\%). Fructose content also increased with induction treatment. Fructose in control condition ranged from 0.05 to $0.75\left(\mathrm{mg} \mathrm{g}^{-1}\right.$ fw), while under induction treatment it varied between 0.08 and $1.10\left(\mathrm{mg} \mathrm{g}^{-1} \mathrm{fw}\right)$. The highest increase in fructose content was recorded in genotypes, Arka Rakshak (433.4 $\%)$ followed by IIHR-2190 (305.2\%) whereas the genotype Arka Abha has recorded lowest fructose content. The Glucose content in control ranged from 0.01 to $0.30\left(\mathrm{mg} \mathrm{g}^{-1} \mathrm{fw}\right)$, while under induction treatment it varied between 0.12 to $0.93\left(\mathrm{mg} \mathrm{g}^{-1} \mathrm{fw}\right)$ significantly highest increase in glucose content over control was recorded in genotypes IIHR-2190 with 784.3 percent. However the genotype Arka Abha recorded lowest glucose content.

Table.1 Effect of temperature induction on sucrose, inositol, fructose and glucose in fourteen tomato genotypes

\begin{tabular}{|c|c|c|c|c|c|c|c|c|c|c|c|c|}
\hline & \multicolumn{3}{|c|}{ Sucrose $(\mathrm{mg} / \mathrm{g} \mathrm{FW})$} & \multicolumn{3}{|c|}{ Inositol (mg/g FW) } & \multicolumn{3}{|c|}{ Fructose (mg/g FW) } & \multicolumn{3}{|c|}{ Glucose (mg/g FW) } \\
\hline & Control & Induced & Mean & Control & Induced & Mean & Control & Induced & Mean & Control & Induced & Mean \\
\hline IIHR-329 & 0.77 & 14.54 & 7.66 & 0.53 & 2.38 & 1.46 & 0.27 & 0.65 & 0.46 & 0.26 & 0.80 & 0.53 \\
\hline IIHR-371 & 3.05 & 12.86 & 7.96 & 0.68 & 2.24 & 1.46 & 0.25 & 0.80 & 0.52 & 0.30 & 0.74 & 0.52 \\
\hline IIHR-369 & 3.92 & 16.90 & 10.41 & 0.35 & 0.90 & 0.62 & 0.73 & 1.10 & 0.92 & 0.15 & 0.28 & 0.21 \\
\hline IIHR-335 & 2.31 & 6.01 & 4.16 & 0.77 & 1.37 & 1.07 & 0.07 & 0.30 & 0.18 & 0.08 & 0.29 & 0.19 \\
\hline IIHR-331 & 1.48 & 8.42 & 4.95 & 0.74 & 1.51 & 1.13 & 0.24 & 0.34 & 0.29 & 0.21 & 0.33 & 0.27 \\
\hline Arka Ananya & 2.43 & 7.41 & 4.92 & 0.79 & 2.49 & 1.64 & 0.36 & 0.57 & 0.46 & 0.28 & 0.57 & 0.43 \\
\hline Abhinava & 1.50 & 4.07 & 2.79 & 0.13 & 0.46 & 0.29 & 0.15 & 0.30 & 0.23 & 0.17 & 0.23 & 0.20 \\
\hline $\begin{array}{l}\text { Arka } \\
\text { Rakshak }\end{array}$ & 0.79 & 5.58 & 3.18 & 0.73 & 2.91 & 1.82 & 0.08 & 0.44 & 0.26 & 0.14 & 0.35 & 0.24 \\
\hline IIHR-2202 & 0.71 & 10.65 & 5.68 & 1.93 & 4.41 & 3.17 & 0.41 & 0.62 & 0.51 & 0.42 & 0.95 & 0.68 \\
\hline IIHR-2190 & 2.99 & 16.90 & 9.94 & 0.23 & 2.90 & 1.57 & 0.16 & 0.65 & 0.41 & 0.01 & 0.12 & 0.06 \\
\hline Vybhav & 0.68 & 0.76 & 0.72 & 0.72 & 1.40 & 1.06 & 0.30 & 0.43 & 0.36 & 0.15 & 0.39 & 0.27 \\
\hline PTR 3 & 4.70 & 13.82 & 9.26 & 0.74 & 1.67 & 1.21 & 0.22 & 0.57 & 0.40 & 0.30 & 0.47 & 0.39 \\
\hline CO-3 & 1.26 & 3.50 & 2.38 & 0.88 & 1.12 & 1.00 & 0.05 & 0.08 & 0.07 & 0.17 & 0.23 & 0.20 \\
\hline Arka Abha & 1.07 & 2.43 & 1.75 & 0.71 & 0.90 & 0.80 & 0.75 & 0.86 & 0.81 & 0.71 & 0.93 & 0.82 \\
\hline Mean & 1.98 & 8.85 & & 0.71 & 1.90 & & 0.29 & 0.55 & & 0.24 & 0.48 & \\
\hline \multicolumn{13}{|l|}{ CD (0.05) } \\
\hline G & \multicolumn{3}{|c|}{1.166} & \multicolumn{3}{|c|}{0.74} & \multicolumn{3}{|c|}{0.159} & \multicolumn{3}{|c|}{0.157} \\
\hline $\mathbf{T}$ & \multicolumn{3}{|c|}{0.441} & \multicolumn{3}{|c|}{0.28} & \multicolumn{3}{|c|}{0.06} & \multicolumn{3}{|c|}{0.059} \\
\hline GxT & \multicolumn{3}{|c|}{1.649} & \multicolumn{3}{|c|}{1.047} & \multicolumn{3}{|c|}{0.225} & \multicolumn{3}{|c|}{0.222} \\
\hline
\end{tabular}

G:Genotype, T:Treatment, GxT: Genotype and treatment interaction 
Fig.1 Temperature induction response on activity of superoxide dismutase (SOD), peroxidise (POD) and catalase (CAT) in fourteen tomato genotypes

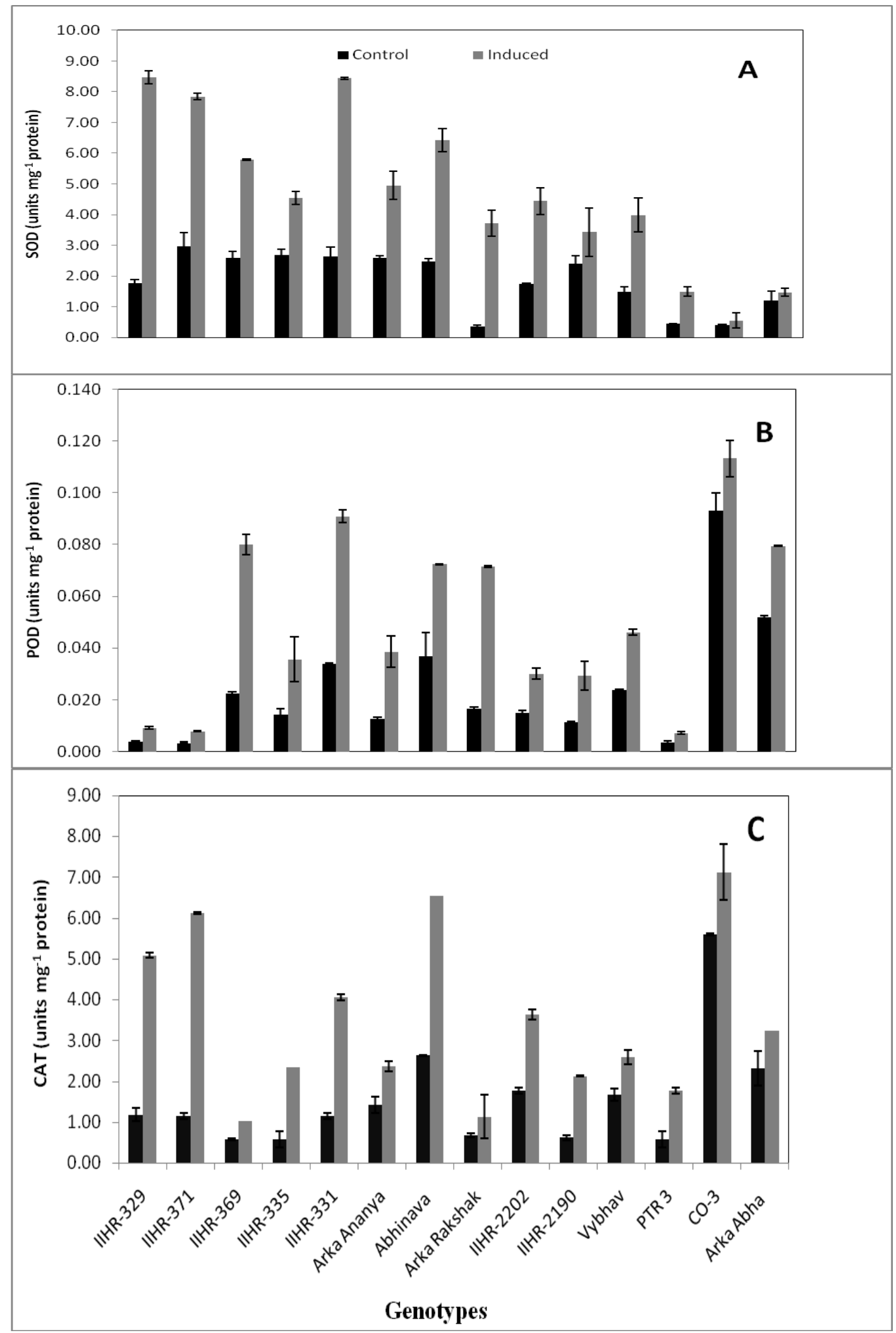


Fig.2 Relationship between Sucrose and POD (A), Inositol and POD (B), Fructose and CAT (C)

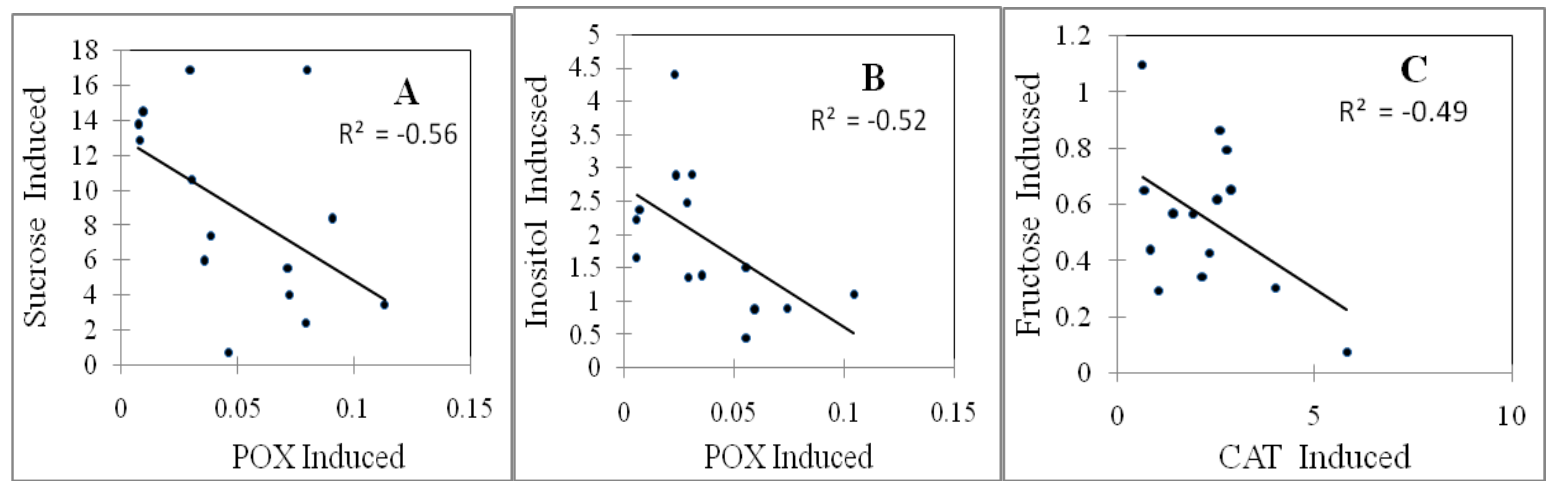

Miguel et al., (2007) reported the increase in glucose and fructose along with high invertase activity in tomato plants when subjected to high temperature stress. The contents of fructose, glucose and sucrose were significantly higher when tomato plants were exposed to $35^{\circ} \mathrm{C}$ for $8 \mathrm{~h}$ (Zhang et al., 2012). It is observed that the accumulation of sugars increases when plants experience any kind of stress, which acts as an important adaptive mechanism to stress conditions (Wahid et al., 2007). The present study has clearly demonstrated that an increase in antioxidant enzymes, SOD, POD and CAT along with osmo-protectants such as sucrose, fructose, glucose and inositol when tomato genotypes were exposed to high temperature stress.

A correlation study was carried out between antioxidant enzymes and sugars to see their relationship when exposed to high temperature stress and A negative correlation was observed in sugars such as sucrose with POD (Fig. 2A), inositol with POD (Fig. 2B) and Fructose with CAT (Fig. 2C) suggesting that increase in sugar content as osmoprotectants are associated with decrease in activity of antioxidant enzymes in tomato genotypes when exposed to high temperature stress. It was also reported in wheat seedlings that external application of low concentration of glucose $(0.1 \mathrm{mM}$ and $0.5 \mathrm{mM})$ enhance the activity of peroxidase, catalase and superoxide dismutase enzymes ( $\mathrm{Hu}$ et al.,
2012). Accumulation of low concentration of soluble sugars, such as glucose and sucrose under stress stimulates the activity of antioxidant enzymes (Boriboonkaset et al., 2012). Similar correlation study between antioxidant enzymes and osmo-protectants has been reported by Rai et al., (2015) in hyacinth bean and Harsh et al., (2016) in moth bean under high temperature stress.

From the present study it can be concluded that the osmoprotectants and antioxidant enzymes play an important role in mitigating damages caused by high temperature stress. The mechanism of the activity of antioxidant enzymes and quantification of sugar accumulation helps in assessing the genotypic variations for their thermo tolerance.

\section{Acknowledgements}

This work is a part of Indian Council for Agriculture Research (ICAR), New Delhi, India, funded project National Initiative on Climate Resilient Agriculture (NICRA). We are grateful to the Director, ICAR-Indian Institute of Horticulture Research (ICARIIHR), Bangalore for the facilities.

\section{References}

Aggarwal, P. K., 2003. Impact of climate change on Indian agriculture. J Plant Biol. 30: 189-198. 
Ayala, A., Muñoz, M.F., and Argüelles, S., 2014. Lipid peroxidation: production, metabolism, and signaling mechanisms of malondialdehyde and 4-hydroxy-2nonenal. Oxid Med Cell Longev. 360438.

Boriboonkaset, T., Theerawitaya, C., Pichakum, A., Cha-um, S., Takabe, T., and Kirdmanee, C. 2012. Expression levels of some starch metabolism related genes in flag leaf of two contrasting rice genotypes exposed to salt stress. Aust J Crop Sci. 6:15791586.

Camejo, D., Alarcon, J. J., Torres, W., Rodriguez, P., and Dell Amico, J. M. 2002. Changes induced by high temperatures in photosynthesis and antioxidant response on two genotypes of tomato (Lycopresicon esculentum M.). Cultivos Tropicales. 23(4): 33-37.

Camejo, D., Rodríguez, P., Morales, M.A., Dell'Amico J.M., Torrecillas, A., and Alarcón, J.J. 2005. High temperature effects on photosynthetic activity of two tomato cultivars with different heat susceptibility. J Plant Physiol. 9: 162.

Crowe, J., Hoekstra, F., and Crowe, L., 1999. Anhydrobiosis. Ann. Rev. Plants. Physiol. 54: 579-599.

Harsh, A., Sharma, Y.K., Joshi, U., Rampuria, S., Singh, G., Kumar, S., and Sharma, R. 2016. Effect of short-term heat stress on total sugars, proline and some antioxidant enzymes in moth bean (Vigna aconitifolia) 61: 57-64.

Hasanuzzaman, M., Nahar, K., and Fujita, M., 2013. Extreme Temperatures, Oxidative Stress and Antioxidant Defense in Plants. In: Vahdati, K., Leslie, C., editors. Abiotic

Stress-Plant Responses and Applications in Agriculture. InTech; Rijeka, Croatia. 169-205.

Hong, S.W., Vierling, E. 2000. Mutants of Arabidopsis thaliana defective in the acquisition of tolerance to high temperature stress. Proceedings of the National Academy of Sciences, USA 97: 4392-4397.

Hu, M., Zhigang, S., Zhengbin, Z., Yingjun, Z., and Hui, L. 2012. Effects of exogenous glucose on seed germination and antioxidant capacity in wheat seedlings under salt stress Plant Growth Regul 68:177-188.

Islam, M. T. 2011. Effect of temperature on photosynthesis, yield attributes and yield of tomato genotypes. International Journal of Experimental Agriculture. 21: 8-11.

Jiang, Y., and Huang, B., 2001. Effects of calcium on antioxidant activities and water relations associated with heat tolerance in two cool-season grasses. J. Exp. Bot. 52: 341-349. doi:10.1093/jexbot/52.355.341

Krasensky, J., and Jonak, C., 2012. Drought, salt, and temperature stress-induced metabolic rearrangements and regulatory networks. J. Exp. Bot. 460.

Larkindale, J., and Huang, B., 2004. Thermotolerance and antioxidant systems in Agrostis stolonifera: involvement of salicylic acid, abscisic acid, cadmium, hydrogen peroxide and ethylene. J. Plant Physiol. 16: 405-413.

Laxman, R.H., Rao, N. K. S., Geeta, B., John sunoj, V.S., Shivashankara K. S., Pavithra, C.B., Dhanyalakshmi, K.H., Manasa, K.M., 2014. Antioxidant enzymes activity and physiological response of tomato (Lycopersicon esculentum Mill.) genotypes under mild temperature stress. Ind J Plant Physiol. 19:161-164.

Laxman, R. H., Srinivasa, R.N.K., Bhatt, R.M., Sadashiva, A.T., John sunoj, V.S., Biradar, G., Pavithra, C.B., Manasa, K.M., Dhanyalakshmi, K.H., 2013. Response of tomato (Lycopersicon esculentum Mill:) 
genotypes to elevated temperature. Journal of Agrometeorology. 15: 38-44.

Laxman, R. H., Sunoj, V.S.J., Biradar, G., Pavithra, C.B., Dhanyalakshmi, K.H., Manasa, K.M., Sadashiva, A.T., Bhatt, R.M., 2018. Growth, reproductive development and yield of tomato (Solanum lycopersicum L.) genotypes under mild temperature elevation. Asian Journal of Botany.

Miguel, A.R., Maria, M.R., Rosa, C., Nicolas, C., Juan, M.R., Luis, R. 2007. Sucrolytic activities in cherry tomato fruits in relation to temperature and solar radiation. Sci. Hort. 113: 244-249.

Mishra, K.B., Iannacone, R., Petrozza, A., Mishra, A., Armentano, N., Vecchia, G.L., et al., 2012. Engineered drought tolerance in tomato plants is reflected in chlorophyll fluorescence emission. Plant Sci. 182:79-86.

Rai, N., Rai, K.K., Tiwari, G. et al., 2015. Changes in free radical generation, metabolites and antioxidant defense machinery in hyacinth bean (Lablab purpureus. L) in response to high temperature stress. Acta Physiol Plant 37: 46.

Rainwater, D. T., Gossett, D. R., Millhollonm, E. P., Hanna, H. Y., Banks, S. W., and Lucas, M. C. (1996). The relationship between yield and the antioxidant defense system in tomatoes grown under heat stress. Free Rad Res. 25: 421-435.

Rathinasabapathi, B. 2000. Metabolic engineering for stress tolerance: installing osmo-protectant synthesis pathways. Annals of Botany. 86, 709716.

Rivero, R. M., Ruiz, J. M., and Romero, L. 2004. Oxidative metabolism in tomato plants subjected to heat stress. J Horti Sci and Biotech. 79, 560-564.

Roitsch, T. 1999. Source-sink regulation by sugar and stress. Curr. Opin. Plant Biol.
2: 198-206.

Rosa, M., Prado, C., Podazza, G., Interdonato, R., González, J.A., Hilal, M., Prado, F.E. 2009. Soluble sugars--metabolism, sensing and abiotic stress: a complex network in the life of plants. Plant Signal Behav.4: 388-93

Gill, S.S., Tuteja, N. 2010. Reactive oxygen species and antioxidant machinery in abiotic stress tolerance in crop plants Plant Physiol Biochem. 48: 909-930

Sairam, R. K., Tyagi, A., 2004. Physiology and molecular biology of salinity stress tolerance in plants. Curr. Sci. 86: 407421.

Sato, S., Peet, M. M., Randolph, G., et al., 2004. Altered flower retention and developmental patterns in nine tomato cultivars under elevated temperature. Scientia Horticulturae. 101: 95-101.

Sato, S., Kamiyama, M., Iwata, T., Makita, N., Furukawa, H. Ikeda, H. 2006. Moderate increase of mean daily temperature adversely affects fruit set of Lycopersicon esculentum by disrupting specific physiological processes in male reproductive development. Ann. Bot. 97:731-738.

Sato, S., Peet, M.M., Thomas, J.F., 2000. Physiological factors limit fruit set of tomato (Lycopersicon esculentum Mill.) under chronic mild heat stress. Plant Cell and Environment. 23: 719-726.

Sawhney, V., Singh, D., 2002. Effect of chemical desiccation at the postanthesis stage on some physiological and biochemical changes in the flag leaf of contrasting wheat genotypes. Field crop Res. 77: 1-6.

Senthil Kumar M and Udayakumar M. 2004. Development of thermotolerant tomato (Lycopersicum esculentum Mill.) lines: an approach based on mutagenesis. $J$. Plant Biol. 31: 139.

Steppuhn, A., and Wackers, F. L. 2004. HPLC sugar analysis reveals the 
nutritional state and the feeding history of parasitoids. Functional Ecology. 18: 812-819.

Vierling, E. 1991. The roles of heat shock proteins in plants. Annu Rev Plant Physiol Plant Mol Biol. 42: 579-620.

Wahid, A., Gelani, S., Ashraf, M., and Foolad, M. 2007. Heat tolerance in plants: an overview. Environ. Exp. Bot. 61: 199-223.

Xu, S., Li, J., Zhang, X., Wei, H., and Cui, L. 2006. Effects of heat acclimation pretreatment on changes of membrane lipid peroxidation, antioxidant metabolites, and ultrastructure of chloroplasts in two cool-season turfgrass species under heat stress. Environ. Exp. Bot. 56: 274-285.

Yuan, Z. C., Haudecoeur, E., Faure, D., Kerr, K. F., and Nester, E. W. 2008.
Comparative transcriptome analysis of Agrobacterium tumefaciens in response to plant signal salicylic acid, indole-3acetic acid and gamma- amino butyric acid reveals signalling cross-talk and Agrobacterium-plant co-evolution. Cell Microbiol.10: 2339-2354.

Zhang J, Jiang X, Li T, et al., 2012. Effect of moderately high temperature stress on photosynthesis and carbohydrate metabolism in tomato (Lycopersicon esculentum L.) leaves. African Journal of Agriculture Research. 7(3): 487-492.

Zhou, R., Yu, X., Kjaer, K.H., Rosenqvist, E., Ottosen, C.O., Wu, Z. 2015. Screening and validation of tomato genotypes under heat stress using Fv/Fm to reveal the physiological mechanism of heat tolerance. Environ Exp Bot. 118: 1-11.

\section{How to cite this article:}

Geeta Biradar, R.H. Laxman, M.R. Namratha, M. Thippeswamy, K.S. Shivashankara, T.K. Roy and Sadashiva, A.T. 2019. Induction Temperature Enhances Antioxidant Enzyme Activity and Osmoprotectants in Tomato. Int.J.Curr.Microbiol.App.Sci. 8(03): 1284-1293. doi: https://doi.org/10.20546/ijcmas.2019.803.152 